\title{
Periarticular Fractures of the Knee in Polytrauma Patients
}

\author{
M.L. Bertrand*, P. Andrés-Cano and F.J. Pascual-López
}

Department of Orthopaedic Surgery and Traumatology. Hospital Costa del Sol. University of Malaga, Spain

\begin{abstract}
Periarticular fractures around the knee are a challenge for the orthopaedic surgeon. When these fractures are presented in the context of a multiple trauma patient, they are even more difficult to manage because the treatment approach depends not only on the fracture itself, but also on the patient's general condition. These fractures, caused by high-energy trauma, present complex fracture patterns with severe comminution and major loss of articular congruity, and are often associated with vascular and nerve complications, particularly in the proximal tibia, due to its anatomical features with poor myocutaneous coverage. They are almost always accompanied by soft tissue injury.

The management of polytrauma patients requires a multidisciplinary team and accurate systemic stabilization of the patient before undertaking orthopaedic treatment. These fractures are usually addressed sequentially, either according to the general condition of the patient or to the local characteristics of the lesions. In recent decades, various fixation methods have been proposed, but there is still no consensus as to the ideal method for stabilizing these fractures. In this paper, we describe the general characteristics of these fractures, the stabilization methods traditionally used and those that have been developed in recent years, and discuss the treatment sequences proposed as most suitable for the management of these injuries.
\end{abstract}

Keywords: Damage control, distal femur, external fixator, knee injuries, locking plates, polytrauma, proximal tibia.

\section{INTRODUCTION}

The lower extremities are the most frequently injured body regions in trauma patients, being affected in $19 \%$ of cases, while the upper extremities are affected in $17.7 \%$ of cases [1]. The presence of lower extremity fractures in patients with multiple injuries worsens prognosis and increases the risk of complications. In many cases, lesions around the knee are also associated with a poor functional outcome [2]. These fractures, affecting the distal region of the femur and the proximal tibia are difficult to handle, even when they occur in isolation. In polytrauma patients, both the initial and the definitive treatments are crucial, as these fractures are associated with many serious complications and situations of functional impairment. An exhaustive review should be performed of the vascular and neurological status of the limb and the status of the surrounding soft tissues, as these injuries are often accompanied by vascular nerve damage and soft tissue injuries. This type of lesion is sometimes so severe as to endanger the leg, and the physician must decide whether to perform an amputation or to reconstruct the limb, in which case determining the most appropriate treatment sequence is essential in order to minimize complications.

The main problem encountered with such patients is that they usually present with life-threatening multiple lesions that can compromise the head, chest, pelvis, etc. and which are also often associated with significant soft tissue injury.

*Address correspondence to this author at the Department of Orthopaedic Surgery and Traumatology, Hospital Costa del Sol, University of Málaga, 29603 Marbella, Malaga, Spain; Tel: +0034 617444 939;

E-mail: mlbertrand@yahoo.es
Therefore, treatment must be performed sequentially, and articular reconstruction cannot be undertaken immediately.

Treatment should be aimed at achieving a balance between rapid, definitive skeletal stabilization, and avoiding potential life-threatening systemic complications, such as fat embolism, acute lung injury and multiple organ failure. The recommended strategy for the assessment and management of multiple trauma patients is well established [3] and it is well known that the damage control of these fractures must be planned carefully so as not to interfere with the subsequent final treatment.

In this chapter, we describe the characteristics of each type of periarticular fracture around the knee (distal femur and proximal tibia fractures), the initial management of these patients and the recommended timing for definitive treatment.

\section{DISTAL FEMUR FRACTURES}

Distal femur fractures are those affecting the distal third of the femur, including the supracondylar and intercondylar regions and extending from the metaphyseal-diaphyseal junction to the articular surface of the knee. Such fractures are rare, accounting for only $0.4 \%$ of all fractures and $3 \%$ of femur fractures [4].

Due to the resistance associated with normal bone mineral density, extraordinary mechanical forces are needed to produce a fracture in the femur. Therefore, such fractures usually affect two population groups: young men, aged about 30 years, and women aged over 70 years. The first group of fractures is related to traffic accidents or the practice of extreme sports, i.e., high-energy trauma, while the fractures in the second group are generally caused by domestic 
accidents, i.e., low-energy trauma. However, polytrauma affecting more elderly patients is becoming increasingly common, and the average age of these patients is now ten years higher than 30 years ago [5].

\section{CLASSIFICATION}

The most widely used fracture classification is that of AO/OTA [6] (Fig. 1), which divides fractures into extra articular, partial articular and bicondylar or complete articular.
A1

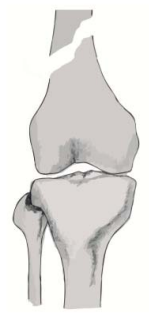

B1

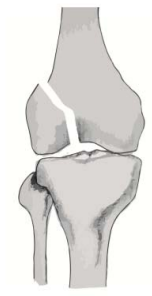

C1

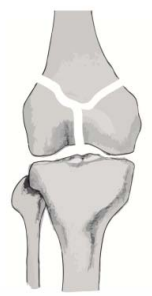

A2

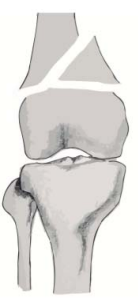

B2

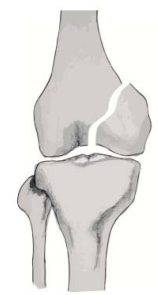

C2

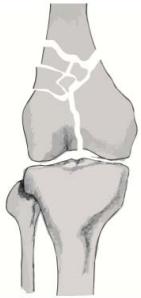

A3

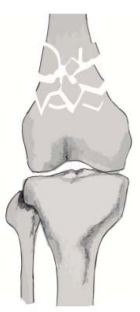

B3

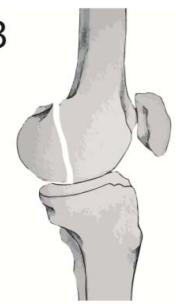

C3

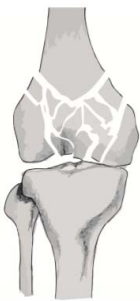

The fractures that are most frequently found in polytrauma patients are the most complex, since these are due to high-energy trauma, the most common types of which are $\mathrm{A} 3$, and especially $\mathrm{C} 2$ and $\mathrm{C} 3$. The $\mathrm{C} 3$ fractures are the most difficult to address, presenting articular and metaphyseal comminution, and can also accompany a frontal plane fracture (Hoffa fracture). The degree of comminution is determined by the energy that caused the fracture and the bone quality of the patient. Being caused by high-energy trauma, besides presenting complex fracture patterns, they are often associated with soft tissue, vascular and nerve injuries, and lesions affecting myocutaneous coverage and/or ligaments. The skin is also affected, to a greater or lesser degree, and open fractures are not uncommon (Fig. 2).

\section{ANATOMY}

To understand the difficult management of these fractures, it is important to understand their anatomy. The anterior cortex of the femoral shaft in the sagittal plane is aligned with the front half of the condyles, while in the posterior region the condyles are behind the diaphyseal cortical bone that is immediately above. The femoral shaft forms an angle of 7-10 degrees with the knee joint, and this is an important consideration to take into account when the reduction of the fracture must be addressed. This region of the femur contains powerful muscles that will displace the fracture, shortening it and diverting it at different angles, depending on the location of the fracture, with the quadriceps, adductors, hamstrings and calf muscles being those primarily involved in this movement. Deviations will take place according to the location of the fracture with respect to the action of the muscles [7]. These factors account for the great difficulty often encountered in aligning or reducing these fractures by indirect, closed or even open procedures.

\section{DIAGNOSIS}

The management of patients with distal femur fractures should be standardized and performed in accordance with ATLS principles, as both young and elderly patients often

Fig. (1). AO/OTA Classification [6].

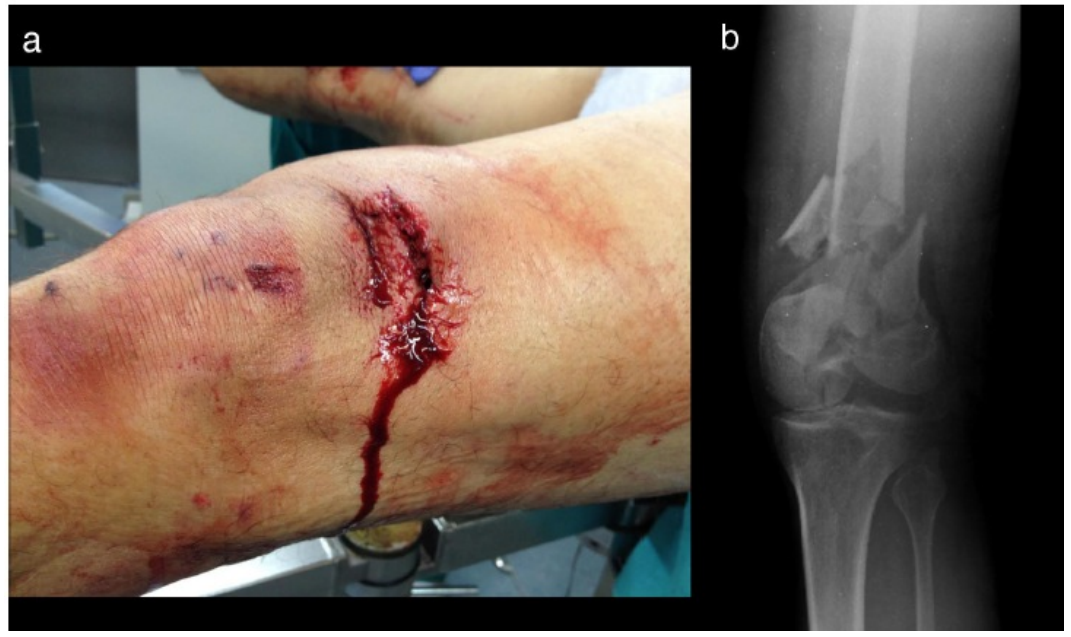

Fig. (2). Polytrauma patient aged 47 years, presenting with an open fracture of the distal femur. (a) Soft tissue injury. (b) Fracture of the distal femur, type $\mathrm{C} 3 \mathrm{AO} / \mathrm{OTA}$. 
present with other, associated, injuries [8]. The inspection must be thorough, including an examination of wounds or lacerations, a neurological and vascular assessment, and take into account that the presence of a pulse does not necessarily indicate the absence of vascular injury [9].

After initial assessment and cardiorespiratory stabilization, and providing the patient's general condition allows it, a radiological study is performed, to obtain anteroposterior and lateral radiographs. In patients with multiple high-energy trauma injuries, a computed tomography (CT) whole body scan is routinely performed [10]. CT is necessary for correct diagnosis and understanding of articular fractures. Nork et al. reported that $38 \%$ of intraarticular fractures of the distal femur present a fracture in the coronal plane (the "Hoffa fragment"), and noted that this fragment is often overlooked in simple radiographs, even by experienced physicians. Therefore, CT is recommended in all cases of distal femur fractures before treatment to ensure that all fracture lines are identified [11, 12].

Vascular lesions associated with limb trauma affect less than $1 \%$ of patients with long bone fracture, although their incidence may increase to $21-42 \%$ in patients with dislocation of the knee [9]. In the absence of obvious signs of vascular compromise, these lesions may easily be missed, with potentially devastating consequences. Therefore, a thorough vascular evaluation is essential. In recent times, advances in CT and Doppler Echo technology have proved to be very useful, as they are highly sensitive and specific in detecting vascular injury. It is important to note that the results obtained depend particularly on the early detection of injury and on immediate treatment [13]. A neurological examination should always be performed before and after any reduction is undertaken.

\section{TREATMENT}

In most countries, polytrauma is one of the leading causes of death in young people. The high morbidity and mortality of these patients has made the question of initial management both a serious concern and a challenge. For this reason, very specific guidelines have been laid down for the action to be taken with such patients, from the very moment of the accident. These principles are based on an algorithm developed by the American College of Surgeons Committee on Trauma, termed Advanced Trauma and Life Support (ATLS). The principles of treatment are divided into four stages: Primary assessment (ABCD) and resuscitation, secondary assessment (from head to toe) and definitive treatment. The aim of these principles is that after the third phase all the problems affecting the patient should be identified. The patient's condition may deteriorate at any stage, and if this occurs, the physician should repeat the ATLS approach, from the start [14].

\section{Damage Control}

Cardiorespiratory stabilization of the patient is essential before initiating surgical treatment. If the trauma patient is physiologically unstable, the femur must be stabilized. In most cases, definitive fixation is not advisable at this early stage, and the most appropriate course of action is orthopaedic damage control, i.e., the external fixation of the fracture in order to restore limb length and achieve the necessary stabilization of the extremity, for general control of the patient's condition, quickly and with little aggression against the soft tissues. This provisional external fixation can also be used for high-energy fractures with severe soft-tissue injury and also in open fractures and in fractures presenting dead tissue and high levels of contamination. This approach makes it possible to treat soft tissue before carrying out the definitive internal fixation (Fig. 3).

The initial management of these fractures, therefore, applying the principles of damage control, should take the form of temporary treatment with external fixation, taking into account the patient's clinical condition. Once systemic and soft tissue problems have been resolved and the fractures stabilized, definitive treatment can be planned. The use of external fixation stabilizes the fracture and the soft tissues by restoring bone length and general alignment, with limited operating time, and without extensive surgical exposure. It also reduces pain and blood loss.

Damage control of distal femur fractures requires the use of an external fixator bridging the knee. The placement of the fixator in these fractures is a fast, straightforward technique that can be performed in the Intensive Care Unit if necessary. An external fixator provides a stability that is relative but sufficient for the patient to be mobilized. However, this technique requires preoperative planning and compliance with certain minimum requirements and principles, as placement is not without complications. Achieving the reduction of a distal femur fracture indirectly by means of ligamentotaxis is very difficult due to the muscle forces acting in this area, and therefore we only seek to align the limb. A shortening of one centimetre is not too important, but in cases where recovery is slow and definitive surgery is postponed for a lengthy period, it could become almost impossible to restore the original length, and so for the most unstable patients our main goal is to maintain the length of the limb. For optimum placement of the fixator, we must plan what type of surgery will be performed as the definitive solution, because if a locking plate is expected to be used in the outer region, the best approach is to place the femur nails in the anterior region [15]. Some authors oppose this approach, as it damages the quadriceps and can provoke adhesions and corresponding posterior stiffness, but it does appear to reduce the risk of infection in the definitive surgery. The nails should be placed as far as possible from the area of the future incision and from the fracture point, equivalent to the space that the future implant is expected to occupy. This approach may decrease the stability and rigidity of the system, but as the treatment is only temporary, this aspect is considered of less importance. In fractures which have a large and highly comminuted distal fragment, there may be considerable mobility with this type of frame construct, and in these cases the possibility of placing the nails closer to the focal point should be considered.

Beltran et al., in a cadaveric study [16], defined a safe zone of $20 \mathrm{~cm}$ in which the nails should be placed in the femur, extending from $5.8 \mathrm{~cm}$. below the trochanter to 7.5 $\mathrm{cm}$. above the upper pole of the patella; a major concern in establishing this safe zone is to avoid penetrating the joint, which may lead to septic arthritis [16]. The nails should be placed in the anterointernal face of the tibia, and the bridge 


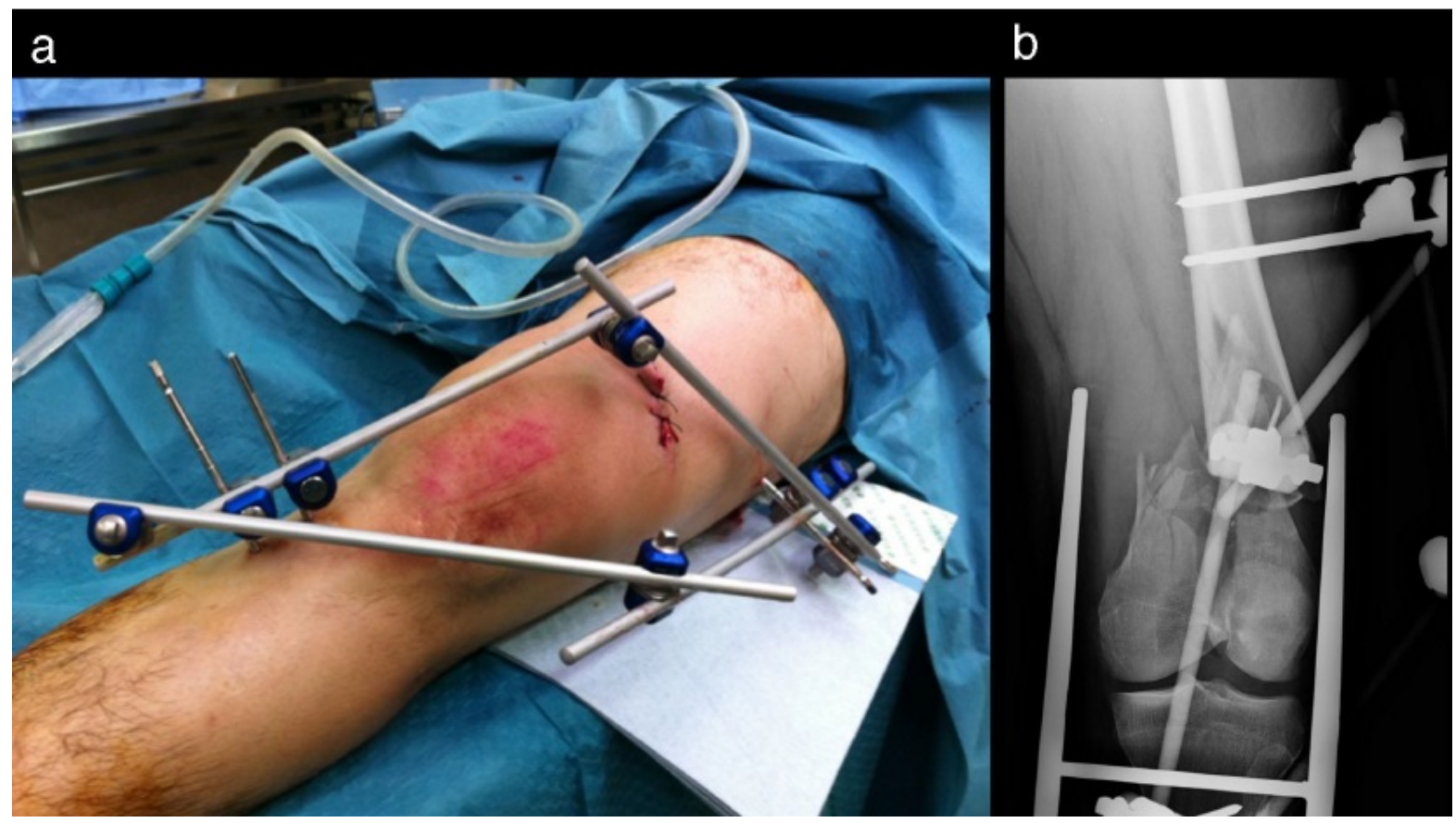

Fig. (3). Damage control in polytrauma patient presenting with supra-intercondylar fracture (type C2 AO/OTA), open femoral fracture, Gustilo grade II. (a) External fixator bridging the knee. (b) Radiographic evaluation.

constructed using a modular system (Fig. 3a). The positioning system should be planned so as not to interfere with healing or posterior debridement of possible injuries.

It is preferable to place the nails manually, avoiding as far as possible the use of a motor, thus decreasing bone necrosis and preventing possible loosening [17]. Although some authors advocate external transfixing systems [18], monolateral systems are less aggressive to soft tissue and facilitate patient management. Finally, to increase the stability of the assembly, a double bar or further nails and rods may be placed in different planes to build a biplanar assembly.

The sequential strategy of temporary external fixation and later conversion to definitive treatment has proven to be a safe method with few complications for the treatment of these patients [19]. Infection of the exit area of the nails is a complication that has been reported in many studies, but this problem has become much less common in recent years. The femur is more commonly affected than the tibia, which could be accounted for by the action of the powerful thigh muscles, which maintain continual traction, provoking stress and irritation at the point where the nails are inserted in the bone, thus increasing the risk of infection [15]. Other possible complications include vascular or nerve damage, either by direct injury when the nail is inserted or by the traction produced when indirect reduction is performed [20].

After damage control, the patient is transferred to the ICU, until full recovery is achieved and the definitive treatment can be initiated.

\section{Definitive Treatment}

When the initial treatment is a temporary external fixation, the optimal timetable for definitive treatment must be decided. During the first four days post-trauma, definitive secondary surgery is not recommended, as immunological changes are continuing and tissue oedema is not yet stabilized. It has been shown that surgery of over three hours' duration on these days is related to multiple organ failure far more often than on days six to eight and that posttraumatic inflammatory response is worsened [21].

Multifragmentary and/or intra-articular distal femoral fractures are subject to deforming muscular forces that make non-surgical treatment a poor choice. The same factors make these fractures very demanding whatever surgical option is adopted, and failure rates are high. Conservative treatment is hardly ever considered, because it obtains worse results than surgical treatment and, moreover, is subject to high rates of complications [22]. Accordingly, this option is only adopted in cases in which the patient cannot tolerate surgery.

Certain basic principles should be considered with respect to this surgery. First, if the fracture is intra-articular, reconstruction of the joint is the essential first step. For this purpose, the knee must remain free and mobile during surgery, because in order to achieve good exposure of the fracture lines, the knee must be in flexion. Stabilization in the frontal plane is not usually difficult, but in the sagittal plane, with the rotation of the condyles, it is much more complicated. Second, the epiphysis must be fixed to the metaphysis, and this is done with the leg in extension. If there is significant comminution, great care should be taken to control rotation and length [23]. It is of crucial importance to restore the alignment in both planes in order to preserve the function of the limb. In consolidated fractures with over 15 degrees of valgus or with any degree of varus, posttraumatic arthritis has been reported [24]. Misalignment in the axial and sagittal planes will affect the kinematics of the knee and its range of motion, while articular mismatch contributes, moreover, to the development of degenerative 
Table 1. Distal femur fracture treatment techniques.

\begin{tabular}{|c|c|c|c|}
\hline Technique & Fixation & Advantages & Disadvantages \\
\hline External fixation & Relative & $\begin{array}{l}\text { * Minimally invasive } \\
\text { * Damage control }\end{array}$ & $\begin{array}{l}* \text { Less stable } \\
* \text { Not as definitive }\end{array}$ \\
\hline Retrograde nail & Relative & * Minimally invasive & $\begin{array}{l}* \text { Not applicable with comminution } \\
* \text { Risk of septic arthritis }\end{array}$ \\
\hline Angled blade plate & Absolute & * High stability & $\begin{array}{l}* \text { No condyle fractures } \\
* \text { Technically demanding }\end{array}$ \\
\hline Dynamic condylar screw & Absolute & $\begin{array}{l}\text { * Easy technique } \\
\text { * Intercondylar compression. }\end{array}$ & * Greater bone loss \\
\hline Submuscular plating systems & Relative & $\begin{array}{l}\text { *Less invasive } \\
* \text { Less joint reconstruction }\end{array}$ & * Technically demanding \\
\hline
\end{tabular}

osteoarthritis. It is essential to achieve mobilization of the knee as soon as possible postoperatively to prevent stiffness and consequent poor results [25].

Various surgical methods may be employed for definitive fixation, depending on the characteristics of the fracture and the patient's condition, including external fixation, retrograde intramedullary nails, open reduction and internal fixation with conventional plates, and closed reduction and percutaneous fixation with locking plates (Table 1).

In general, external fixation is not indicated as the definitive treatment of these fractures, particularly of intraarticular fractures. Controlling alignment and stabilization is difficult with this technique and poor results are obtained; furthermore, joint component fixation cannot be achieved, and so a femur-tibia bridge system is required to immobilize the fracture, thus increasing the risk of stiffness. External fixation in the femur does not offer the same results as in the tibia, and the results obtained as definitive treatment for distal femur fractures are usually disappointing [8]. The definitive treatment of fractures of the femur with external fixation until complete consolidation of the fracture is associated with a high risk of complications, such as nonunion, deep infection around the nails and stiffness of the knee [26].

Retrograde intramedullary nailing is a form of relative stabilization that promotes callus formation in the metaphyseal segment. Although this method is traditionally considered to be indicated exclusively for extra-articular fractures, after design changes the indications were extended to fractures with intra-articular involvement [27]. In cases of fractures with articular fragments, compression screws are used to achieve absolute stability of the articular segment, while retrograde nailing provides relative stability to the metaphyseal-diaphyseal segment. The disadvantage of this technique is that it provides little stiffness in flexion/extension and in the control of the varus/valgus of the distal segment, especially when the fracture is more distal and the articular fragment is smaller.

Although retrograde nailing is not indicated for complex intra-articular fractures, this technique has the advantage of being a closed one. Nevertheless, it is intra-articular, which means there is a risk of septic arthritis if infection occurs [23]. Another difficulty encountered in the use of intramedullary nails is that of maintaining the fracture reduction whatever the diameter of the nail; the nail is shorter than the distal metaphysis of the femur, and so it does not reduce the fracture. In consequence, the fracture must be reduced by closed, percutaneous or open techniques.

At the opposite end of the stability spectrum is the approach based on open reduction and internal fixation. This technique is based on achieving the anatomic reduction of each of the fragments of the fracture and on fixation with plates and screws. The traditional approach to open reduction and internal fixation is to use implants based on a blade-plate angle of $95^{\circ}$ and a dynamic compression plate. The $95^{\circ}$ blade-plate structure produces the medial compression of the metaphyseal fracture after diaphyseal fixation is obtained by the plate, due to the difference in angle between the plate and the distal extremity of the femur. Optimising this effect requires a perfectly reconstructed medial pillar [23], which is practically impossible in fractures with significant comminution and therefore this is not a good choice of implant in fractures that are complex or in which the condyles are severely affected, as these circumstances make it impossible to insert the plate. This implant technique is technically demanding, as the point and direction of insertion of plate entry are critical, but it can give good results in experienced hands.

Vandenbussche et al. recently published two multicentre studies, one retrospective and one prospective, comparing the treatment of distal fractures of the femur using four different fixation methods: $95^{\circ}$ blade-plate, dynamic condylar screw (DCS) plates, retrograde intramedullary nailing and locking condylar plates; no statistically significant differences were found in infection rates, early complications, the need for reoperation for bone grafting, fracture healing time or functional outcomes, but the patients treated with the $95^{\circ}$ plate had a lower significantly rate of early reoperation due to the failure of the implant, and so it was concluded that these plates provide a fixation method that is simple, stable, and cheap, and that they are being unfairly neglected [28].

The DCS, or dynamic compression plate, method has the advantage of being technically simple to perform. Because the screw is cannulated, bone trauma is limited and there is good resistance to fatigue. However, the screw hole is large and this may compromise bone stock and produce rotational 
instability. In cases of major metaphyseal comminution, these plates are associated with a high risk of varus collapse [29].

Due to the biological environment of the articular segment, it is very rarely adversely affected by direct reduction, and problems of the consolidation of articular fragments rarely occur. Therefore, reduction should be performed by direct visualization. However, the circumstances are different for the reduction of the metaphysis and the diaphysis, these areas being sensitive to the biological aggression produced by direct reduction. For this reason, in recent years efforts have been made to develop a new generation of plates that will allow indirect reduction without producing direct exposure of the fracture point. The aim of this approach is to overcome the high rate of complications observed with direct reduction techniques, which require all the fragments of the fracture to be exposed before reduction, with the consequent biological aggression.

Percutaneous osteosynthesis techniques, or minimally invasive plate osteosynthesis (MIPO), lie at the midpoint between intramedullary fixation and open reduction and internal fixation. Many types of implants have been developed to facilitate the percutaneous application of a plate in the lateral region of the femur. This technique and these implants rely on the correct positioning of the plate to achieve fixation of the distal articular segment with locking screws, and then use the plate to achieve the correct alignment of the femoral shaft. This type of fixation produces relative stability, and leads to the consolidation of the metaphysis with callus. It is commonly used in fractures with severe metaphyseal comminution, in osteoporotic fractures in elderly patients and in periprosthetic fractures. However, the use of this percutaneous technique requires open reduction so that screws can be used for the fixation of the articular fragments. With locking plates, the submuscular plate can be inserted without affecting the metaphyseal fractures, but still enabling exposure of the joint, the anatomical reduction of the fragments and osteosynthesis with compression screws. This is an important consideration and this procedure should be carried out before the epiphyseal locking screws are inserted. These plates, with screws locked to them, either at a fixed angle or, in the latest generation, at a variable angle, form a fixed angle between each screw hole and the plate, functioning as an "internal fixator" and therefore do not require support from underlying bone, and so have less impact on its blood supply. These implants incorporate many new features that make them potentially favourable for the treatment of fractures of the distal femur. Nevertheless, they also present a number of limitations, the most important being that this technique is technically demanding. Many studies have concluded that considerable surgical experience is necessary for optimal results to be achieved with such implants. In recent years, many studies have confirmed the utility of this method in the treatment of complex distal fractures [30-33] (Fig. 4).

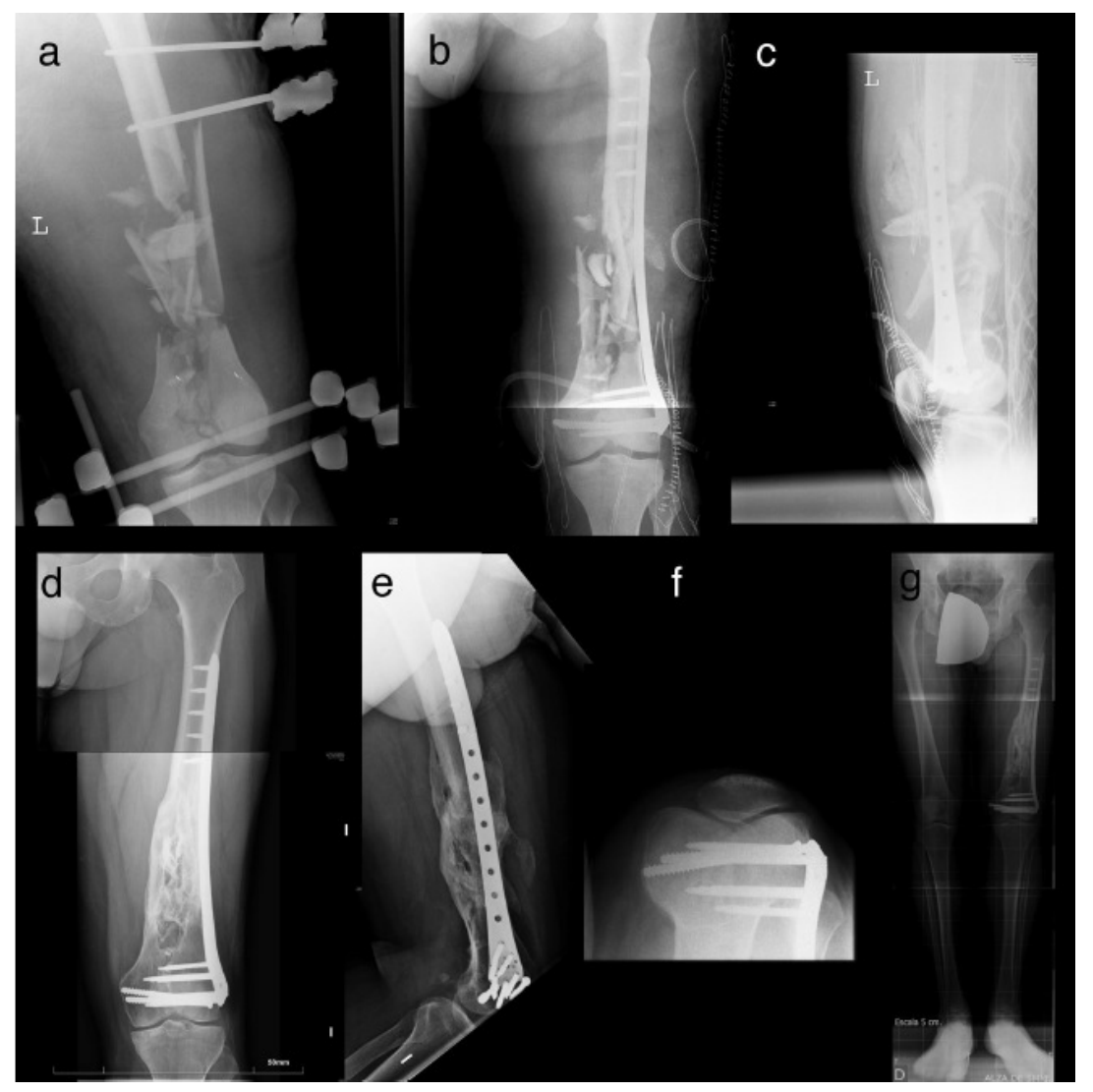

Fig. (4). Sequential treatment of distal femoral fracture in polytrauma patient. (a) Damage control. (b) Definitive fixation with locked plate at 15 days. Anteroposterior view. (c) Definitive fixation with locked plate at 15 days. Lateral view. (d) Radiograph evaluation after seven years. Anteroposterior view. (e) Radiograph evaluation after seven years. Lateral view. (f) Radiograph evaluation after seven years. Axial view. (g) Radiograph evaluation after seven years. Teleradiography of lower limbs. 
Table 2. Distal femur fracture treatment techniques: bibliography.

\begin{tabular}{|c|c|c|}
\hline Author / Year & Aims & Results \\
\hline Zlowodzki et al. 2006 [35] & $\begin{array}{l}\text { To compare diverse fixation techniques: } \\
\text { traditional compression plate, anterograde } \\
\text { nailing, retrograde nailing, submuscular } \\
\text { locked internal fixation, external fixation }\end{array}$ & $\begin{array}{l}\text { No differences observed in non-union, infection, failure of fixation, and } \\
\text { revision surgery. } \\
\text { Locked submuscular implants can reduce infection rates, but may increase } \\
\text { the risk of fixation failure and the need for revision surgery, versus } \\
\text { compression techniques. } \\
\text { Surgeons with more experience can significantly reduce the need for } \\
\text { revision surgery. }\end{array}$ \\
\hline Markmiller et al. 2004 [36] & $\begin{array}{l}\text { To compare LISS }{ }^{1} \text { plate and } \\
\text { intramedullary nail techniques }\end{array}$ & No significant difference. \\
\hline Hartin et al. 2006 [37] & $\begin{array}{l}\text { To compare retrograde nail and fixed- } \\
\text { angle plate techniques }\end{array}$ & $\begin{array}{l}\text { Similar rates of consolidation. } \\
\text { Higher complication rate with plates. } \\
\text { Higher rate of infection, delayed healing and greater stiffness with plates. }\end{array}$ \\
\hline Christodoulou et al. 2005 [38] & $\begin{array}{l}\text { To compare mini-open } \mathrm{DCS}^{2} \text { and } \\
\text { intramedullary nail techniques }\end{array}$ & $\begin{array}{l}\text { Same consolidation rate. } \\
\text { Less blood loss, shorter surgery time and shorter hospital stay, with nails. } \\
\text { Higher rate of complications with DCS }\end{array}$ \\
\hline Heiney et al. 2009 [39]. & $\begin{array}{l}\text { Using cadavers, to compare } \\
\text { intramedullary nail, DCS and locking } \\
\text { condylar plate techniques. }\end{array}$ & $\begin{array}{l}\text { Greater axial stiffness with nails than DCS and much greater than with the } \\
\text { locking condylar plate }\end{array}$ \\
\hline Hahn et al. 2002 [40] & $\begin{array}{l}\text { To compare } 95^{\circ} \text { blade-plate and LISS } \\
\text { plate techniques. }\end{array}$ & No difference. \\
\hline Thomson et al. 2008 [41] & $\begin{array}{l}\text { To compare } \mathrm{ORIF}^{3} \text { and retrograde nail } \\
\text { techniques. }\end{array}$ & $\begin{array}{l}\text { Poorly-located grafting and consolidation much greater with ORIF. } \\
\text { No differences in terms of infection or non-union. }\end{array}$ \\
\hline Markmiller 2004 [42] & $\begin{array}{l}\text { To compare intramedullary nail and LISS } \\
\text { with conventional plate techniques. }\end{array}$ & $\begin{array}{l}\text { No difference in range of motion, rate of pseudo-arthritis, rate of poorly- } \\
\text { located consolidation, rate of infection or functional ability. }\end{array}$ \\
\hline Wu et al. 1992 [43] & $\begin{array}{l}\text { To compare Grosse-Kempf interlocking } \\
\text { nails and osteosynthesis with conventional } \\
\text { plates techniques. }\end{array}$ & $\begin{array}{l}\text { Higher rate of consolidation and more satisfactory functional results with } \\
\text { the nails. } \\
\text { Risk of breakage of the distal transverse screw hole. }\end{array}$ \\
\hline Vallier et al. 2012 [44] & $\begin{array}{l}\text { To compare } 95^{\circ} \text { blade-plate and locked } \\
\text { condylar plate techniques. }\end{array}$ & No differences. \\
\hline Hierholzer et al. 2011 [45] & $\begin{array}{l}\text { To compare retrograde nail and LISS } \\
\text { plate techniques }\end{array}$ & $\begin{array}{l}\text { No differences in consolidation time, non-union rate or postoperative } \\
\text { complications. }\end{array}$ \\
\hline
\end{tabular}

However, others, such as Ehlinger et al., have concluded that this type of plate has not met the expectations raised and does not solve all the problems encountered in distal fractures of the femur. Thus, after several decades, this approach is still not adopted universally [34].

At present, there is no general consensus regarding how fractures should be stabilized and which fixation method is most suitable. Many comparative studies in this respect have been conducted, but none have drawn convincing, clear-cut conclusions, due to the considerable variability in the data analysed and in the methods used for evaluating the results obtained. Thus, it is very difficult to derive a meaningful interpretation of the outcomes reported (Table 2).

Griffin et al. are currently preparing a Cochrane review to determine the most appropriate forms of treatment for distal femur fractures in adults [46]. This review will examine randomized controlled trials on the effects, whether beneficial or harmful, of different interventions for fractures of the distal femur. A comparison will be made of different

${ }^{1}$ LISS - less invasive stabilization system.

${ }^{2}$ DCS - dynamic condylar screws.

${ }^{3}$ ORIF - open reduction and internal fixation. methods of conservative treatment, of surgical treatment versus conservative treatment and of different methods of surgical treatment. In the near future, this review may provide reliable data to guide physicians in their treatment decisions.

\section{FRACTURES OF THE PROXIMAL TIBIA}

Proximal tibial fractures, in the context of multiple trauma, are typically caused by high-energy trauma. This not only produces complex fracture patterns, in most cases with significant comminution, articular impact and metaphysealdiaphyseal dissociation, but also - and characteristically in this type of fracture - major soft-tissue involvement, open or closed, since this anatomical region has little cutaneous muscle cover. These fractures, moreover, are frequently associated with ligamentous injuries, and require careful treatment planning because they often provoke residual pain, functional problems and the development of premature osteoarthritis [47].

Tibial plateau fractures constitute $2 \%$ of all fractures, and amount to $9.2 \%$ of all fractures of the tibia [48]. Anatomically, the lateral plateau is higher and more convex 
than the medial plateau, and has a posterior slope angle of 7$10^{\circ}$. As a result of this anatomy, lateral tibial plateau fractures are more frequent, regardless of the lesion mechanism [49]. However, in the context of polytrauma, when patients are usually young and have suffered highenergy traumas with compression forces and valgus, medial plateau fractures occur more frequently, often with significant impact on the soft tissues and ligaments and provoking neurovascular injury [50].

\section{CLASSIFICATION}

Several approaches have been proposed to classify these fractures. The traditional method is the Schatzker classification (Fig. 5), which has the advantage of being highly reproducible.
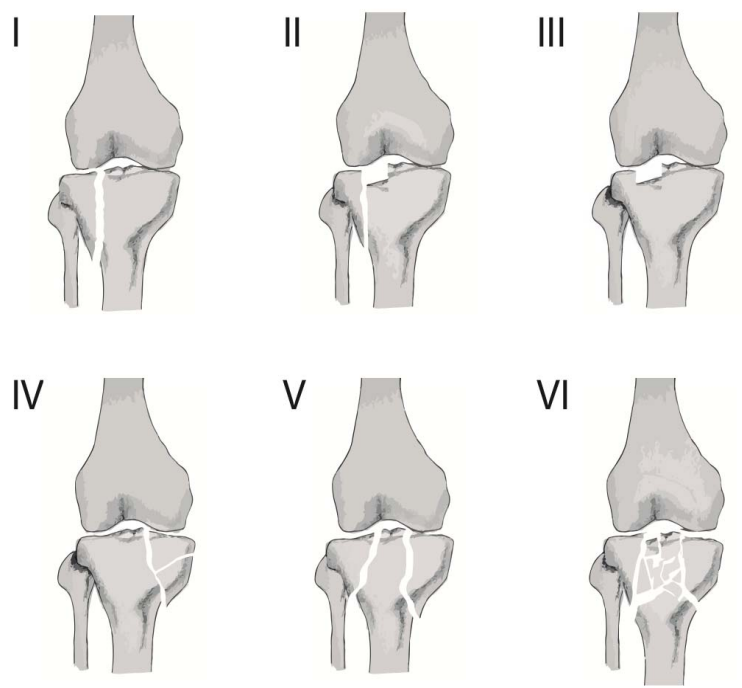

Fig. (5). Schatzker classification of fractures of the proximal tibia.

However, the AO/OTA classification (Table 3) is becoming increasingly popular, despite its complexity, because it is more accurate [51].

Table 3. AO classification of proximal tibia fractures.

\begin{tabular}{|l|l|l|}
\hline \multicolumn{3}{|c|}{ AO Classification } \\
\hline \hline $\begin{array}{l}41 \\
\text { Extra-articular }\end{array}$ & A1 & Avulsion \\
\hline & A2 & Metaphyseal simple \\
\hline & A3 & Metaphyseal multifragmentary \\
\hline $\begin{array}{l}\text { B } \\
\text { Partial articular }\end{array}$ & B1 & Pure split \\
\hline & B2 & Pure depression \\
\hline & B3 & Split depression \\
\hline $\begin{array}{l}\text { C: } \\
\text { Complete articular }\end{array}$ & C1 & Simple, metaphyseal simple \\
\hline & C2 & Simple metaphyseal, multifragmentary \\
\hline & C3 & Multifragmentary \\
\hline
\end{tabular}

Nevertheless, both classifications have limitations: neither of them describes fractures of the posterior column, which are very common in high-energy traumas. In response to this problem, a new proposal has been made, in which the tibial plateau is divided into three columns: medial, lateral and posterior [52]. The boundaries of these three columns are based on imaginary lines: one from the anterior tibial tubercle to the tibial spines separates the lateral column from the medial column, and another line from the anterior-most part of the head of the fibula to the posteromedial area of the internal tibial crest separates the posterior column from the medial and lateral columns [53] (Fig. 6). In terms of equivalence to the Schatzker classification, the following correspondence could be established: Schatzker III $=0$ columns, Schatzker I and II = 1 column (lateral), Schatzker IV $=2$ columns (medial and posterior), Schatzker V and VI $=3$ columns (medial, lateral and posterolateral) (Fig. 7). Under these classifications, the types of fractures most often encountered in polytrauma patients are types $\mathrm{V}$ and $\mathrm{VI}$ Schatzker, and $41 \mathrm{~B} 3$ and $\mathrm{C}$ in the $\mathrm{AO}$ classification.

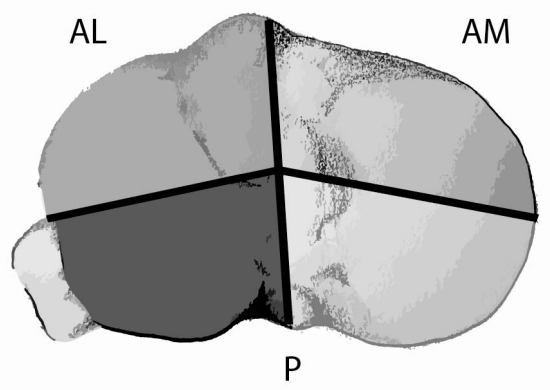

Fig. (6). Three-column classification in proximal tibial fractures. AL: Lateral column. AM: Medial column. P: Posterior column
।

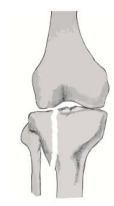

॥

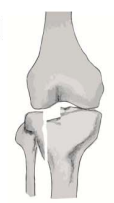

III

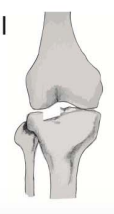

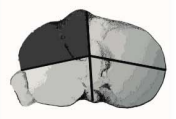

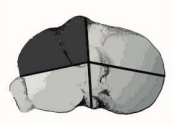

$\mathrm{V}$

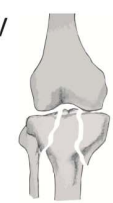

$\mathrm{VI}$

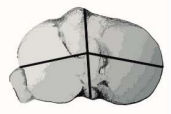

IV
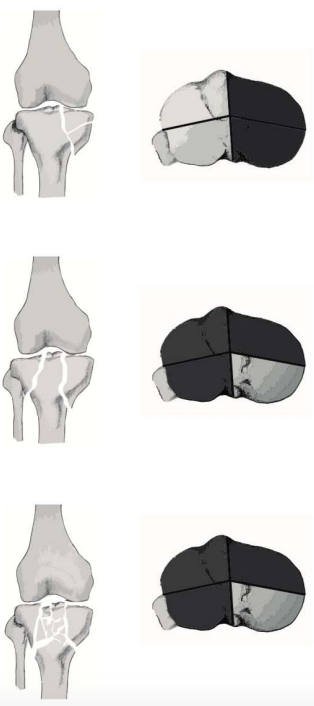
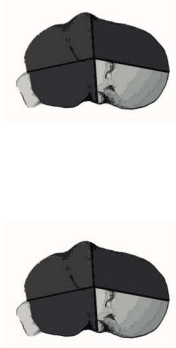

Fig. (7). Equivalence between the Schatzker classification and the three-column classification.

As mentioned above, an important characteristic of these fractures by high-energy trauma is the associated impact on the soft tissues; therefore, it is important to quantify these lesions, as this consideration will often determine the 
Table 4. Tscherne and oestern classification [54].

\begin{tabular}{|c|l|}
\hline \multicolumn{2}{|c|}{ Closed Fractures } \\
\hline 0 & No lesions evident in soft tissue \\
\hline 1 & Indirect superficial injury \\
\hline 2 & Abrasion, blisters and oedema, by direct action. \\
\hline 3 & Crushing or severe damage, associated with vascular injury or compartment syndrome. \\
\hline Open Fracture & \\
\hline 1 & Injury by bone fragment, no bruising. \\
\hline 2 & Injury by circumscribed bruising with moderate contamination \\
\hline 3 & Major soft tissue damage. Neurovascular injury, partial ischaemia. Severe contamination. Compartment syndrome. \\
\hline 4 & Partial or total amputation. Vascular injury with complete ischaemia. \\
\hline
\end{tabular}

treatment of choice. In this respect, most authors use the Tscherne and Oestern classification [54] (Table 4).

\section{DIAGNOSIS}

The management of polytrauma patients, as discussed above, should be standardized and conducted in accordance with ATLS principles. Clinical assessment of these fractures requires, first, a consideration of the condition of the skin and surrounding soft tissue, as this is a key factor in deciding the optimum approach to treatment. The skin is usually bruised and/or eroded. Certain wounds indicate open fractures and, depending on the time elapsed since the trauma, there may be blisters, usually haemorrhagic (Fig. 8). It is essential to assess the vascular and nerve status and to identify any sign of possible compartment syndrome. In addition, a neurological examination should be performed, focusing especially on the role of the external popliteal sciatic nerve, which is the most commonly affected.

Simple two-plane radiography provides an approximate view of the morphology of the fracture. However, for an accurate diagnosis, a CT scan must be performed to determine the three dimensions of the lesion, to classify them accurately and to plan the treatment $[50,55,56]$. It is very important to assess the coronal slice in order to determine the impact on the different pillars. CT should be performed with the fracture under traction, especially for fractures presenting severe comminution.

The use of magnetic resonance imaging (MRI) for the initial diagnosis is a much-debated issue; while it is true that a high percentage of these fractures are associated with ligament injuries, the latter are not usually treated in the acute phase. Moreover, the role of arthroscopy in the treatment of these fractures casts further doubt on the actual usefulness of MRI [57]. When these fractures are suffered by a polytrauma patient, it is imperative to perform a CT with contrast. This, together with the Eco-Doppler test, is an effective means of studying vascular lesions.

\section{TREATMENT}

The management of polytrauma patients with multiple injuries affecting the lower extremities requires resuscitation and haemodynamic assessment with cardiorespiratory stabilization before considering any orthopaedic treatment.

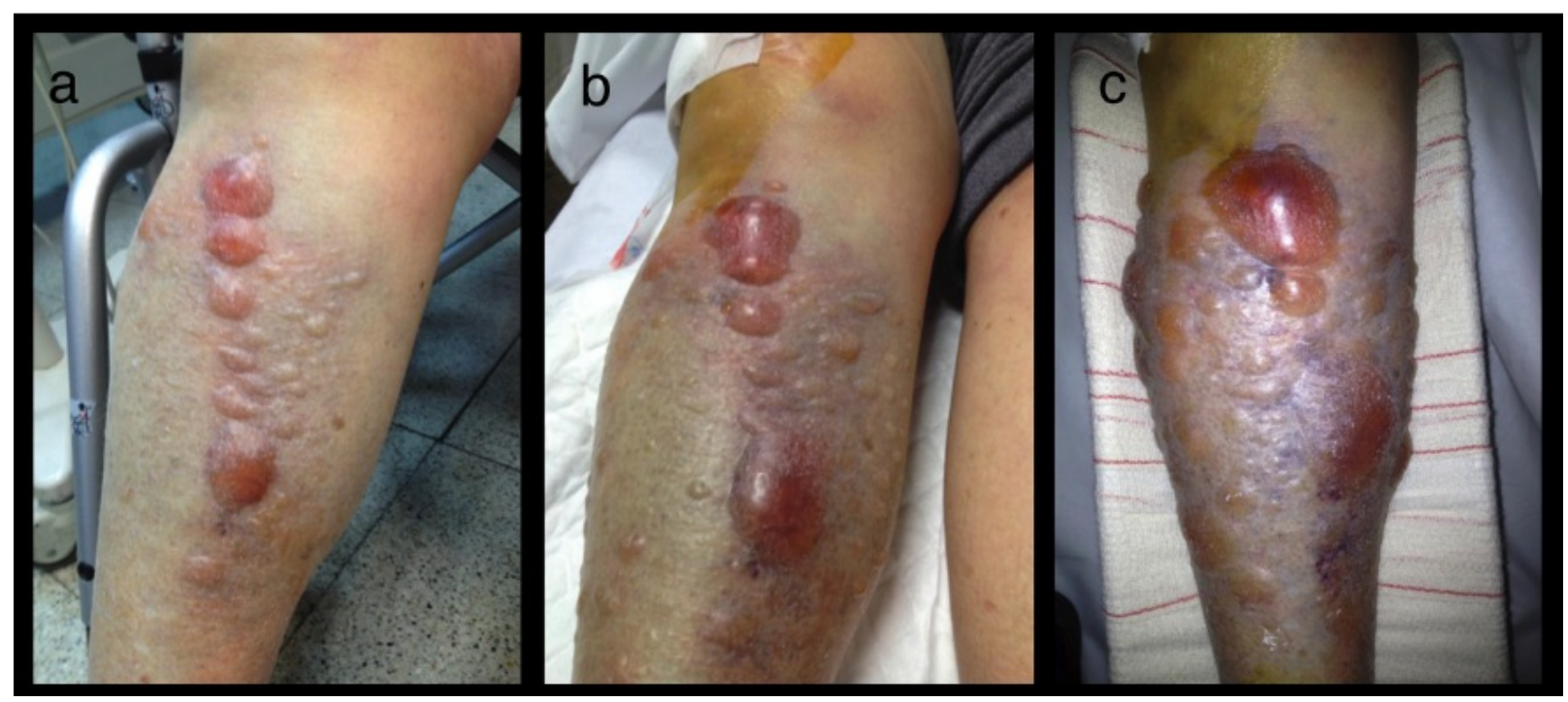

Fig. (8). Evolution of soft-tissue status in tibial plateau fracture. (a) On arrival at the emergency department. (b) Three hours after trauma. (c) Six hours after trauma. 
The main treatment goals with these fractures are to restore articular congruity and thus to achieve metaphyseal stabilization and good metaphyseal-diaphyseal alignment, with a method that is not aggressive to the soft tissues and enables the rapid recovery of mobility.

Proximal tibial fractures produced by high-energy trauma, Schatzker type V or VI, usually require surgery. They are often associated with open fractures or soft tissue injuries, type I or II according to the Tscherne and Oestern classification. Regardless of the patient's general condition and of the indication for damage control, it is usually beneficial to conduct a sequential treatment, consisting of initial external fixation and subsequent definitive fixation [58]. In these cases, the external fixator may bridge the knee, from the femur to the tibia, or a hybrid external fixator may be used, composed of a proximal ring maintaining the metaphysis by means of transfixing needles, together with a monolateral fixator in the tibial diaphysis so that both structures stabilize the metaphyseal-diaphyseal dissociation. This treatment with a hybrid external fixator at the outset is used in cases in which this fixator might enable definitive fixation.

The aim of sequential treatment, in unstable trauma patients, is to stabilize the fracture until the patient's systemic condition allows definitive treatment. When there is soft-tissue involvement, external fixation makes it possible to wait until the situation is resolved, when definitive fixation can be undertaken (Fig. 9). Sequential treatment has proven to be beneficial in proximal tibial fractures, regardless of the patient's general condition, because of the risk of complications secondary to soft-tissue injuries, providing a safe and effective method of reducing the risk of infection (from $80 \%$ to less than $8 \%$ ) [59].

The definitive surgical treatment of these fractures is currently based on two fundamental procedures: closed,

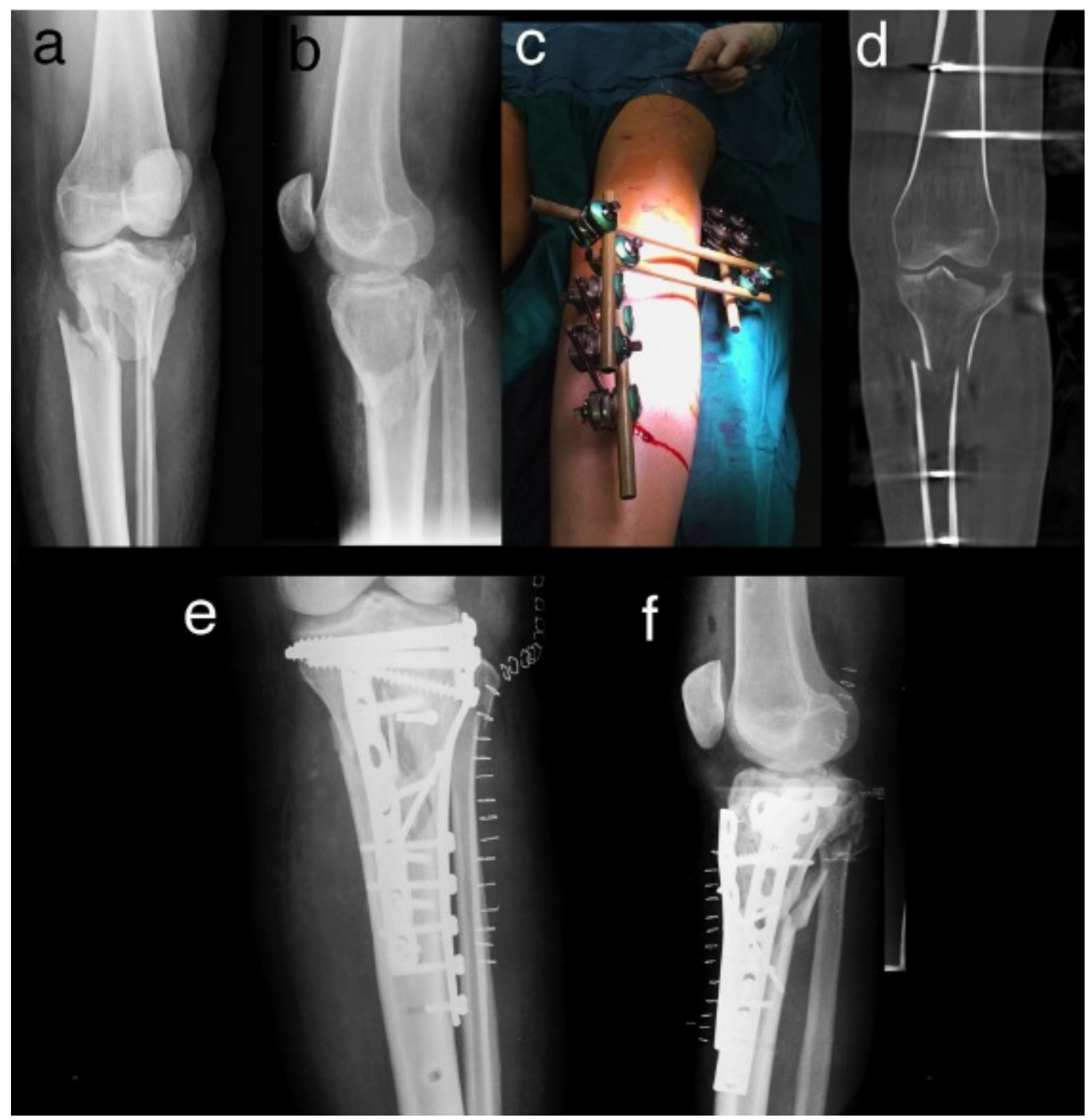

Fig. (9). Sequential treatment of tibial plateau fracture. (a) Radiograph of fracture, type Schatzker VI. Anteroposterior view. (b) Lateral radiograph. (c) External fixation, bridging the knee. (d) External fixation (CT). (e) Definitive osteosynthesis. Anteroposterior view. (f) Definitive osteosynthesis. Lateral view. 
indirect reduction and external fixation with hybrid external fixators, or open reduction and internal fixation by means of osteosynthesis with double plates or even a single lateral plate. The plates may be locked or non-locked. The indication for each of the treatments remains an open question, and no study has yet established that one is superior to the other.

\section{Hybrid External Fixation}

Hybrid external fixation, thus, can be used as an initial treatment in cases where damage control is indicated, although even in cases in which the patient's general condition requires prompt treatment, it is preferable to use a fixator bridging the knee. Hybrid external fixation is technically more demanding and can be used when it is expected to be the definitive treatment, provided the patient's condition allows this. It is also used in cases where the patient's condition is stable and definitive treatment can be undertaken, but open reduction and internal fixation cannot be performed due to the delicate status of the soft tissues. When this technique is used as the definitive treatment it sometimes avoids the need for the patient to undergo secondary surgery. These fixators can also be used as the secondary treatment after an initial stabilization period with a knee-bridging fixator.

The use of the hybrid external fixator requires indirect reduction of the fracture by ligamentotaxis, and repair of the articular surface. This is achieved indirectly, through "windows", and maintained by means of percutaneous cannulated screws, stabilization of the metaphysis by transfixing needles bonded to the ring, and diaphysealmetaphyseal stabilization by attaching the ring to the linear fixator, which is then connected to the tibial shaft, thus providing stability with respect to the fracture (Fig. 10). Comparing this with double-plate internal fixation, some studies have reported a lower rate of deep infections [60,61], but a slight increase in superficial infections [60,62], partly due to the poor initial condition of the tissues, together with an increased incidence of malunion and of traumatic arthritis [63].

\section{Open Reduction and Internal Fixation}

The technique used conventionally for treating complex fractures of the tibial plateau is that of open reduction and internal fixation with lateral and medial plates. In most cases this treatment requires large incisions with significant devitalization of tissue, resulting in numerous complications. However, the situation has improved markedly in recent years with the use of sequential treatment in which the knee is initially bridged by external fixation, after which internal fixation is performed when the soft tissue problems have been overcome.

Although some studies have reported a higher incidence of deep infections with this technique of open reduction and internal, double-plate fixation $[50,64]$, others have observed good results when this sequential treatment is applied [58].

The approach adopted must be carefully considered; while the use of a single midline incision in order to insert the two plates has been associated with high rates of complications $[65,66]$, the use of two surgical approaches, an inner posterior one and an outer anterior one, makes it possible to visualize both articular surfaces and the fixation, with absolute fracture stability and minimal risks, in comparison with the single-path approach. It has been suggested that this osteosynthesis technique, with two plates and a two-way approach, should be the technique of choice after initial stabilization with external fixation [67, 68], although other authors believe this technique poses a greater risk when the bone is osteoporotic, as this very rigid assembly may weaken the bone in the areas of bone-screw union [69].

In recent years, less invasive techniques have been developed, seeking to avoid the complications that may arise with large-scale approaches requiring double-plate internal fixation. These alternative techniques include the hybrid external fixator (discussed above), minimally invasive plate osteosynthesis (MIPO) [70] and fixation by means of anatomical locking plates. Although no studies have yet drawn firm conclusions in this respect, a systematic review by $\mathrm{Yu}$ et al. found that fractures treated with a hybrid external fixator more commonly present traumatic arthritis, while those treated with internal fixation plates more often have valgus deformity. Nevertheless, these authors stress the need to conduct larger-scale studies to confirm their results [63]. The minimally-invasive use of a single plate reduces the incidence of infection and nonunion, because the periosteum is retained intact. Biomechanical studies have associated the coronal alignment of the fracture with the position of the proximal screws: thus, it has been reported that angulations in which the articular surface is greater than $5^{\circ}$ increase the rate of misalignments in the coronal plane [71]. However, studies comparing this form of osteosynthesis with the double-plate approach have obtained very diverse results [72]. While the use of these plates under the MIPO approach does indeed reduce soft tissue damage, no statistically significant differences have been reported to show that MIPO outperforms the double-plate method in terms of reduced infection rates. On the other hand, it seems to be related to poorer reduction results, misalignments, the loss of reduction and varus displacement [73].

It is important to determine whether or not the posterior column is affected, and if so, whether the impact is medial or lateral, as the treatment to be applied is influenced by these considerations. Differing reports have been made of the incidence of posterior fragments in a bicondylar fracture. In one recent study, the incidence of posterolateral fragments was found to be $44 \%$, that of posteromedial fragments, $30-$ $60 \%$ and that of isolated posterior fragments, $7 \%$ [74]. The fixation of osteromedial fragments by osteosynthesis can be achieved by using a medial plate, as the screws through this plate are capable of maintaining good reduction of the fragment; moreover, if this element is omitted, this may result in less reduction and in misalignment of the fracture, especially when the displacement is $\geq 5 \mathrm{~mm}$ or the angulation in the sagittal plane is $\geq 73^{\circ}$ [52]. By contrast, in the case of the posterolateral fragment, osteosynthesis is technically more complex because of the anatomy of the case (the fibular head and the external peroneal sciatic nerve) and because it is usually found in a vertical position. In these cases, osteosynthesis through a lateral plate is complicated, often requiring additional osteosynthesis with a posterior 

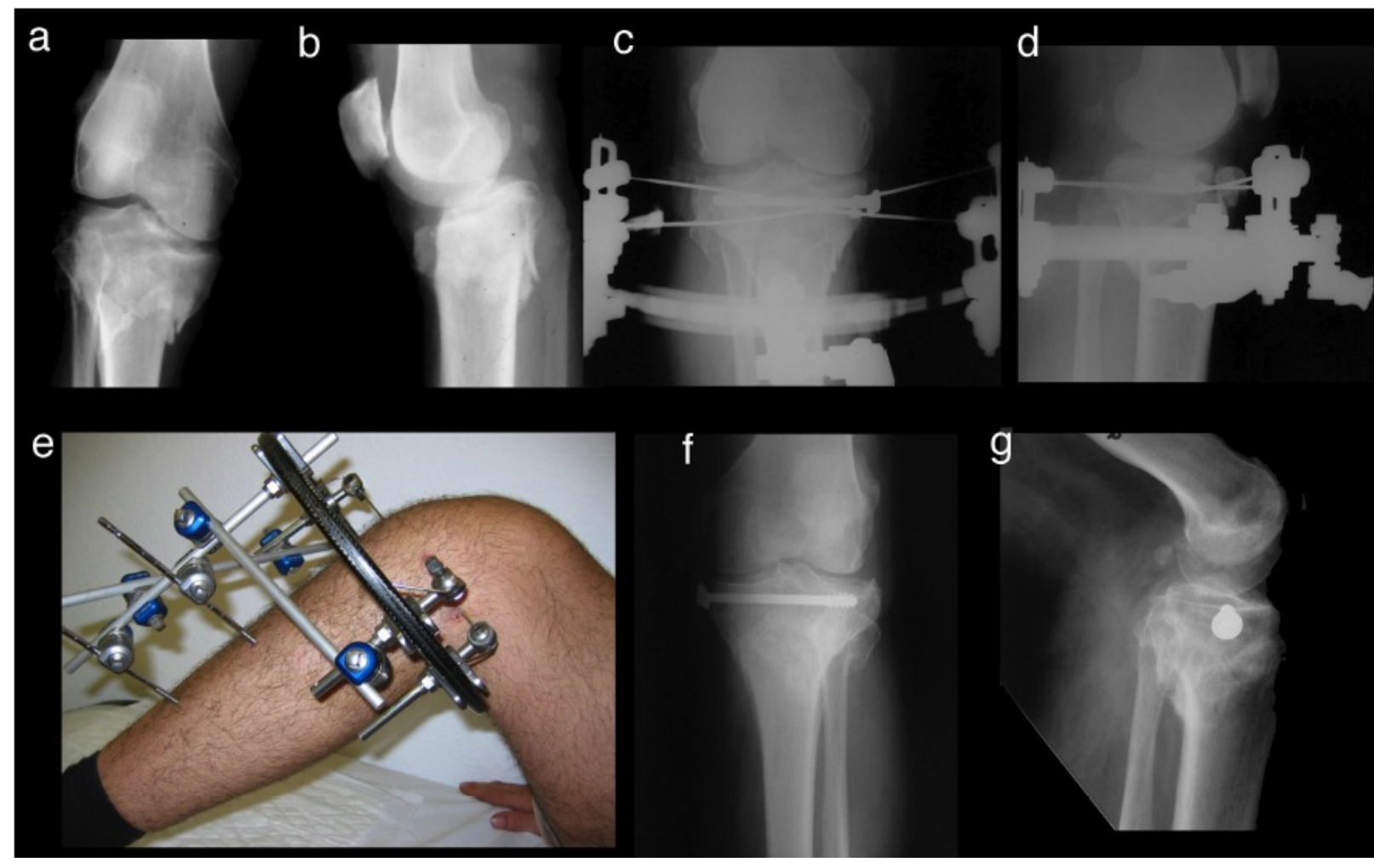

Fig. (10). Definitive treatment of tibial plateau fracture with hybrid external fixator. (a) Tibial plateau fractures, type Schatzker VI. Anteroposterior view. (b) Tibial plateau fractures, type Schatzker VI. Lateral view. (c) Fixation by external hybrid fixator. Anteroposterior view. (d) Fixation by external hybrid fixator. Lateral view. (e) Articular balance with hybrid external fixator at six weeks. (f) Evolution at two years after fracture. Anteroposterior view. (g) Evolution at two years after fracture. Lateral view.

plate, addressed through a posterolateral approach [75-77] or a modified posterior one [53].

In recent years, arthroscopy has been increasingly used in treating proximal tibia fractures, in order to improve reduction quality and to avoid extensive approaches. This technique provides greater diagnostic certainty and enables the treatment, if necessary, of meniscal or ligamentous injuries. In more complex fractures (types $\mathrm{V}$ and VI), arthroscopy does present a greater risk of fluid extravasation with increased intracompartmental pressures. However, some authors advocate its use in complex fractures and have reported satisfactory results [78, 79].

Many comparative studies have been conducted, of all possible treatment combinations, but at present none constitutes an unquestionable reference in deciding whether to employ one technique or another. A Cochrane review is currently being prepared, which will compare external fixation, on the one hand, and closed reduction with internal fixation, on the other, as well as the different types of internal fixation and the role played by arthroscopy in the latter [80].

Ligament and meniscal injuries are relatively common in complex fractures of the tibial plateau. The incidence of meniscal lesions is over $60 \%$ when the plateau is depressed by more than $5 \mathrm{~mm}$ [81]. The only indications for surgery in the acute phase are the fracture of the tibial spines and, probably, injuries in the postero-external angle. Other lesions should be addressed during the first three weeks. In cases of posterior cruciate ligament injury, it is better to reconstruct it than to attempt a repair [82].

\section{TIMING}

The time needed to complete definitive fixation is a contentious issue. In this respect, most studies have examined the conversion of external fixation to intramedullary nailing, and little has been reported on the conversion to internal osteosynthesis in periarticular fractures. It is not known exactly when is the best time to perform definitive fixation without increasing the risk of infection. The risk factors of infection and malunion are not well established, which makes assessment of this question even more difficult. Bhandari et al. reviewed the published data in this respect to determine the relationship between the length of time a fixator is left in position and the rate of infection. In nine studies, the overall infection rate reported was $3.7 \%$, in 191 fractures with less than 28 days of external fixation; this rate increased to $22.1 \%$ when the external fixation was retained for more than 28 days. It was noted that the patients whose conversion was performed after a longer interval may have originally presented more severe injuries or other medical problems that contraindicated an earlier conversion; this circumstance might also increase the rate of infection [83].

Therefore, the moment at which to carry out the definitive fixation of a periarticular lesion that has been temporarily stabilized with external fixation is a major clinical dilemma. Various factors must be considered: the 
condition of the soft tissues, the nature of the initial injury (i.e., whether it is open or closed), the possible need for major surgical debridement, the association of wounds due to open fasciotomies, the location of the nails in the previouslyattached external fixators and their status (i.e., the presence or absence of secretion around the nail), the mechanical stability of the external fixator, bone loss, soft tissue loss, the association with neurovascular injury, and the presence or absence of infection. Although these concepts may refer to any periarticular lesion, specific anatomic regions, such as the tibial plateau, may present higher rates of complications. It is often the injury itself and the status of the soft tissues that contribute most significantly to poor outcomes. More specifically, it is the lack of abundant soft tissue around these areas that makes them difficult to manage. It is not known how long the external fixation can be retained safely before there is an increased risk of infection after conversion to definitive fixation, and so in practice, it is best to convert as soon as the general situation and local issues allow. Sometimes it is advisable to remove the fixator, to debride the exit area of the nails and to place the patient in traction until it is considered that the definitive osteosynthesis can be performed without an increase in complications. Nowotarski et al. showed that external fixation could be safely converted to internal fixation in a single-stage procedure without provoking significant infection. However, when conversion is performed after three weeks, this can have a negative influence on joint reconstruction and fracture healing [84].

\section{CONCLUSION}

Periarticular fractures around the knee remain a difficult problem for orthopaedic surgeons. These fractures are usually caused by high-energy trauma, with very complex fracture patterns and major soft-tissue involvement, especially at the level of the proximal tibia, with high rates of immediate and/or late complications.

The main recommendation is that treatment should be performed sequentially by external fixation, bridging the knee, with subsequent definitive conversion in accordance with the patient's general condition or as required by injuries to associated soft tissues. Many treatment techniques have been proposed and there is still no clear consensus as to their exact indication. In recent years, the trend has been to prefer less invasive techniques, but there is still no clear evidence that these obtain better results. Accordingly, the ultimate decision taken will depend on the type of fracture, the patient's characteristics and the outlook of the surgeon responsible for the treatment.

\section{ACKNOWLEDGEMENTS}

The authors thank Dr Manuel Angel Valdés-Vilchez for his excellent technical assistance in the design and preparation of the manuscript figures.

We thank the Research and Development Department of the Hospital Costa del Sol for the reviewing the English version of this manuscript.

\section{CONFLICT OF INTEREST}

The authors confirm that this article content has no conflict of interest.

\section{REFERENCES}

[1] Banerjee M, Bouillon B, Shafizadeh S, et al. Epidemiology of extremity injuries in multiple trauma patients. Injury 2013; 44(8): 1015-21.

[2] Zelle BA, Brown SR, Panzica M, et al. The impact of injuries below the knee joint on the long-term functional outcome following polytrauma. Injury 2005; 36(1): 169-77.

[3] D'Alleyrand JC, O'Toole RV. The evolution of damage control orthopedics: current evidence and practical applications of early appropriate care. Orthop Clin North Am 2013; 44(4): 499-507.

[4] Court-Brown CM, Caesar B. Epidemiology of adult fractures: a review. Injury 2006; 37(8): 691-7.

[5] Evans JA, van Wessem KJ, McDougall D, Lee KA, Lyons T, Balogh ZJ. Epidemiology of traumatic deaths: comprehensive population-based assessment. World J Surg 2010; 34(1): 158-63.

[6] Marsh JL, Slongo TF, Agel J, et al. Fracture and dislocation classification compendium - 2007: orthopaedic trauma association classification, database and outcomes committee. J Orthop Trauma 2007; 21(10 Suppl): S1-133.

[7] Gwathmey FW, Jr., Jones-Quaidoo SM, Kahler D, Hurwitz S, Cui Q. Distal femoral fractures: current concepts. J Am Acad Orthop Surg 2010; 18(10): 597-607.

[8] Obakponovwe O, Kallala R, Stavrou PZ, Harwood P, Giannoudis $P$. The management of distal femoral fractures: a literature review. Orthop Traumatol Surg Res 2012; 26: 3 .

[9] Perron AD, Brady WJ, Sing RF. Orthopedic pitfalls in the ED: vascular injury associated with knee dislocation. Am J Emerg Med 2001; 19(7): 583-8.

[10] Huber-Wagner S, Lefering R, Qvick LM, et al. Effect of wholebody CT during trauma resuscitation on survival: a retrospective, multicentre study. Lancet 2009; 373(9673): 1455-61.

[11] Nork SE, Segina DN, Aflatoon K, et al. The association between supracondylar-intercondylar distal femoral fractures and coronal plane fractures. J Bone Joint Surg Am 2005; 87(3): 564-9.

[12] Arastu MH, Kokke MC, Duffy PJ, Korley RE, Buckley RE. Coronal plane partial articular fractures of the distal femoral condyle: current concepts in management. Bone Joint J 2013; 95$\mathrm{B}(9)$ : 1165-71.

[13] Halvorson JJ, Anz A, Langfitt M, et al. Vascular injury associated with extremity trauma: initial diagnosis and management. J Am Acad Orthop Surg 2011; 19(8): 495-504.

[14] van Olden GD, Meeuwis JD, Bolhuis HW, Boxma H, Goris RJ Clinical impact of advanced trauma life support. Am J Emerg Med 2004; 22(7): 522-5.

[15] Oh JK, Hwang JH, Sahu D, Jun SH. Complication rate and pitfalls of temporary bridging external fixator in periarticular communited fractures. Clin Orthop Surg 2011; 3(1): 62-8.

[16] Beltran MJ, Collinge CA, Patzkowski JC, et al. The safe zone for external fixator pins in the femur. J Orthop Trauma 2012; 26(11): 643-7.

[17] Green SA. Complications of external skeletal fixation. Clin Orthop Relat Res. 1983(180): 109-16.

[18] Sala F, Capitani D, Castelli F, La Maida GA, Lovisetti G, Singh S. Alternative fixation method for open femoral fractures from a damage control orthopaedics perspective. Injury 2010; 41(2): 1618.

[19] Parekh AA, Smith WR, Silva S, et al. Treatment of distal femur and proximal tibia fractures with external fixation followed by planned conversion to internal fixation. J Trauma 2008; 64(3): 7369.

[20] Staeheli GR, Fraser MR, Jr., Morgan SJ. The dangers of damage control orthopedics: a case report of vascular injury after femoral fracture external fixation. Patient Saf Surg 2012; 6: 7.

[21] Pape H, Stalp M, v Griensven M, Weinberg A, Dahlweit M, Tscherne H. Optimal timing for secondary surgery in polytrauma patients: an evaluation of 4,314 serious-injury cases. Chirurg 1999; 70(11): 1287-93. 
[22] Butt MS, Krikler SJ, Ali MS. Displaced fractures of the distal femur in elderly patients. Operative versus non-operative treatment. J Bone Joint Surg Br 1996; 78(1): 110-4.

[23] Ehlinger M, Ducrot G, Adam P, Bonnomet F. Distal femur fractures. Surgical techniques and a review of the literature. Orthop Traumatol Surg Res 2013; 99(3): 353-60.

[24] Pettine KA. Supracondylar fractures of the femur: long-term follow-up of closed versus nonrigid internal fixation. Contemp Orthop 1990; 21(3): 253-61.

[25] Gwathmey FW, Jr., Jones-Quaidoo SM, Kahler D, Hurwitz S, Cui Q. Distal femoral fractures: current concepts. J Am Acad Orthop Surg 2010; 18(10): 597-607.

[26] Forster MC, Komarsamy B, Davison JN. Distal femoral fractures: a review of fixation methods. Injury 2006; 37(2): 97-108.

[27] Seifert J, Stengel D, Matthes G, Hinz P, Ekkernkamp A, Ostermann PA. Retrograde fixation of distal femoral fractures: results using a new nail system. J Orthop Trauma 2003; 17(7): 48895.

[28] Vandenbussche E, LeBaron M, Ehlinger M, Flecher X, Pietu G, Sofcot. Blade-plate fixation for distal femoral fractures: a casecontrol study. Orthop Traumatol Surg Res 2014; 100(5): 555-60.

[29] Stover M. Distal femoral fractures: current treatment, results and problems. Injury 2001; (32 Suppl 3): SC3-13.

[30] Liu F, Tao R, Cao Y, et al. The role of LISS (less invasive stabilisation system) in the treatment of peri-knee fractures. Injury 2009; 40(11): 1187-94.

[31] Batista BB, Salim R, Paccola CA, Kfuri MJ. Internal fixators: a safe option for managing distal femur fractures? Acta Ortop Bras 2014; 22(3): 159-62.X

[32] Weight M, Collinge C. Early results of the less invasive stabilization system for mechanically unstable fractures of the distal femur (AO/OTA types A2, A3, C2, and C3). J Orthop Trauma 2004; 18(8): 503-8

[33] Kregor PJ, Stannard JA, Zlowodzki M, Cole PA. Treatment of distal femur fractures using the less invasive stabilization system: surgical experience and early clinical results in 103 fractures. J Orthop Trauma 2004; 18(8): 509-20

[34] Ehlinger M, Dujardin F, Pidhorz L, et al. Locked plating for internal fixation of the adult distal femur: Influence of the type of construct and hardware on the clinical and radiological outcomes. Orthop Traumatol Surg Res 2014; 100(5): 549-54.

[35] Zlowodzki M, Bhandari M, Marek DJ, Cole PA, Kregor PJ. Operative treatment of acute distal femur fractures: systematic review of 2 comparative studies and 45 case series (1989 to 2005). J Orthop Trauma 2006; 20(5): 366-71.

[36] Markmiller M, Konrad G, Sudkamp N. Femur-LISS and distal femoral nail for fixation of distal femoral fractures: are there differences in outcome and complications? Clin Orthop Relat Res 2004; (426): 252-7.

[37] Hartin NL, Harris I, Hazratwala K. Retrograde nailing versus fixedangle blade plating for supracondylar femoral fractures: a randomized controlled trial. ANZ J Surg 2006; 76(5): 290-4.

[38] Christodoulou A, Terzidis I, Ploumis A, Metsovitis S, Koukoulidis A, Toptsis C. Supracondylar femoral fractures in elderly patients treated with the dynamic condylar screw and the retrograde intramedullary nail: a comparative study of the two methods. Arch Orthop Trauma Surg 2005; 125(2): 73-9.

[39] Heiney JP, Barnett MD, Vrabec GA, Schoenfeld AJ, Baji A, Njus GO. Distal femoral fixation: a biomechanical comparison of trigen retrograde intramedullary (im) nail, dynamic condylar screw (DCS), and locking compression plate (LCP) condylar plate. J Trauma 2009; 66(2): 443-9.

[40] Hahn U, Prokop A, Jubel A, Isenberg J, Rehm KE. LISS versus condylar plate. Kongressbd Dtsch Ges Chir Kongr 2002; 119: 498504.

[41] Thomson AB, Driver R, Kregor PJ, Obremskey WT. Long-term functional outcomes after intra-articular distal femur fractures: ORIF versus retrograde intramedullary nailing. Orthopedics 2008; 31(8): 748-50.

[42] Markmiller M, Konrad G, Sudkamp N. Femur-LISS and distal femoral nail for fixation of distal femoral fractures: are there differences in outcome and complications? Clin Orthop Relat Res 2004; (426): 252-7.

[43] Wu CC, Shih CH. Treatment of femoral supracondylar unstable comminuted fractures. Comparisons between plating and Grosse-
Kempf interlocking nailing techniques. Arch Orthop Trauma Surg 1992; 111(4): 232-6.

[44] Vallier HA, Immler W. Comparison of the 95-degree angled blade plate and the locking condylar plate for the treatment of distal femoral fractures. J Orthop Trauma 2012; 26(6): 327-32.

[45] Hierholzer C, von Ruden C, Potzel T, Woltmann A, Buhren V. Outcome analysis of retrograde nailing and less invasive stabilization system in distal femoral fractures: a retrospective analysis. Indian J Orthop 2011; 45(3): 243-50.

[46] Griffin XL, Parsons N, Zbaeda MM, McArthur J. Interventions for treating fractures of the distal femur in adults. Cochrane Database Syst Rev 2013; 6: CD010606.

[47] Wang SQ, Gao YS, Wang JQ, Zhang CQ, Mei J, Rao ZT. Surgical approach for high-energy posterior tibial plateau fractures. Indian $\mathbf{J}$ Orthop 2011; 45(2): 125-31.

[48] Lasanianos NG, Garnavos C, Magnisalis E, Kourkoulis S, Babis GC. A comparative biomechanical study for complex tibial plateau fractures: nailing and compression bolts versus modern and traditional plating. Injury 2013; 44(10): 1333-9.

[49] Berkson EM, Virkus WW. High-energy tibial plateau fractures. J Am Acad Orthop Surg 2006; 14(1): 20-31.

[50] Mallina R, Kanakaris NK, Giannoudis PV. Peri-articular fractures of the knee: an update on current issues. Knee 2010; 17(3): 181-6.

[51] Maripuri SN, Rao P, Manoj-Thomas A, Mohanty K. The classification systems for tibial plateau fractures: how reliable are they? Injury 2008; 39(10): 1216-21.

[52] Higgins TF, Kemper D, Klatt J. Incidence and morphology of the posteromedial fragment in bicondylar tibial plateau fractures. J Orthop Trauma 2009; 23(1): 45-51.

[53] Luo CF, Sun H, Zhang B, Zeng BF. Three-column fixation for complex tibial plateau fractures. J Orthop Trauma 2010; 24(11): 683-92.

[54] Oestern HJ, Tscherne H. Physiopathology and classification of soft tissue lesion. Hefte Unfallheilkd 1983; 162: 1-10

[55] $\mathrm{Hu}$ YL, Ye FG, Ji AY, Qiao GX, Liu HF. Three-dimensional computed tomography imaging increases the reliability of classification systems for tibial plateau fractures. Injury 2009; 40(12): 1282-5.

[56] Weil YA, Gardner MJ, Boraiah S, Helfet DL, Lorich DG. Posteromedial supine approach for reduction and fixation of medial and bicondylar tibial plateau fractures. J Orthop Trauma 2008; 22(5): 357-62.

[57] Chan YS, Chiu CH, Lo YP, et al. Arthroscopy-assisted surgery for tibial plateau fractures: 2- to 10-year follow-up results. Arthroscopy 2008; 24(7): 760-8

[58] Egol KA, Tejwani NC, Capla EL, Wolinsky PL, Koval KJ. Staged management of high-energy proximal tibia fractures (OTA types 41): the results of a prospective, standardized protocol. J Orthop Trauma 2005; 19(7): 448-55; Discussion 56.

[59] Barei DP, Nork SE, Mills WJ, Henley MB, Benirschke SK. Complications associated with internal fixation of high-energy bicondylar tibial plateau fractures utilizing a two-incision technique. J Orthop Trauma 2004; 18(10): 649-57.

[60] Pun TB, Krishnamoorthy VP, Poonnoose PM, Oommen AT, Korula RJ. Outcome of Schatzker type V and VI tibial plateau fractures. Indian J Orthop 2014; 48(1): 35-41

[61] Ferreira N, Marais LC. Bicondylar tibial plateau fractures treated with fine-wire circular external fixation. Strategies Trauma Limb Reconstr 2014; 9(1): 25-32.

[62] Sales JG, Soleymaopour J, Ansari M, Afaghi F, Goldust M. Treatment results of bicondylar tibial fractures using hybrid external fixator. Pak J Biol Sci 2013; 16(10): 491-5.

[63] $\mathrm{Yu} \mathrm{L}$, Fenglin Z. High-energy tibial plateau fractures: external fixation versus plate fixation. Eur J Orthop Surg Traumatol 2014

[64] Rademakers MV, Kerkhoffs GM, Sierevelt IN, Raaymakers EL, Marti RK. Operative treatment of 109 tibial plateau fractures: fiveto 27-year follow-up results. J Orthop Trauma 2007; 21(1): 5-10.

[65] Young MJ, Barrack RL. Complications of internal fixation of tibial plateau fractures. Orthop Rev 1994; 23(2): 149-54

[66] Mallik AR, Covall DJ, Whitelaw GP. Internal versus external fixation of bicondylar tibial plateau fractures. Orthop Rev 1992; 21(12): 1433-6

[67] Bendayan J, Noblin JD, Freeland AE. Posteromedial second incision to reduce and stabilize a displaced posterior fragment that can occur in Schatzker Type V bicondylar tibial plateau fractures. Orthopedics 1996; 19(10): 903-4 
[68] Barei DP, Nork SE, Mills WJ, Henley MB, Benirschke SK. Complications associated with internal fixation of high-energy bicondylar tibial plateau fractures utilizing a two-incision technique. J Orthop Trauma 2004; 18(10): 649-57.

[69] Lasanianos NG, Garnavos C, Magnisalis E, Kourkoulis S, Babis GC. A comparative biomechanical study for complex tibial plateau fractures: nailing and compression bolts versus modern and traditional plating. Injury 2013; 44(10): 1333-9.

[70] Prasad GT, Kumar TS, Kumar RK, Murthy GK, Sundaram N. Functional outcome of Schatzker type V and VI tibial plateau fractures treated with dual plates. Indian J Orthop 2013; 47(2): 18894.

[71] Oh JK, Hwang JH, Varte L, et al. Locking plate in proximal tibial fracture: a correlation between the coronal alignment of tibia and joint screw angle. Yonsei Med J 2013; 54(3): 720-5.

[72] Lee MH, Hsu CJ, Lin KC, Renn JH. Comparison of outcome of unilateral locking plate and dual plating in the treatment of bicondylar tibial plateau fractures. J Orthop Surg Res 2014; 9(1): 62 .

[73] Lee TC, Huang HT, Lin YC, Chen CH, Cheng YM, Chen JC. Bicondylar tibial plateau fracture treated by open reduction and fixation with unilateral locked plating. Kaohsiung J Med Sci 2013; 29(10): 568-77.

[74] Sohn HS, Yoon YC, Cho JW, Cho WT, Oh CW, Oh JK. Incidence and fracture morphology of posterolateral fragments in lateral and bicondylar tibial plateau fractures. J Orthop Trauma 2015; 29(2): 91-7.

[75] Lobenhoffer P, Gerich T, Bertram T, Lattermann C, Pohlemann T, Tscheme H. Particular posteromedial and posterolateral approaches for the treatment of tibial head fractures. Unfallchirurg 1997; 100(12): 957-67.
[76] Frosch KH, Balcarek P, Walde T, Sturmer KM. A modified posterolateral approach for the treatment of tibial plateau fractures. Operative Orthopadie und Traumatologie 2010; 22(1): 107-19.

[77] Chen HW, Liu GD, Ou S, Zhao GS, Pan J, Wu LJ. Open reduction and internal fixation of posterolateral tibial plateau fractures through fibula osteotomy-free posterolateral approach. J Orthop Trauma 2014; 28(9): 513-7.

[78] Burdin G. Arthroscopic management of tibial plateau fractures: surgical technique. J Orthop Surg Res 2013; 99(1 Suppl): S208-18.

[79] Chan YS, Yuan LJ, Hung SS, et al. Arthroscopic-assisted reduction with bilateral buttress plate fixation of complex tibial plateau fractures. Arthroscopy 2003; 19(9): 974-84.

[80] McNamara IR, Hing CB, Smith TO, Clark AB, Nielsen DM, Donell S. Surgical fixation methods for tibial plateau fractures (Protocol). Cochrane Database Syst Rev 2012; 3: doi: 10.1002/14651858.CD009679.

[81] Stannard JP, Lopez R, Volgas D. Soft tissue injury of the knee after tibial plateau fractures. J Knee Surg 2010; 23(4): 187-92.

[82] Levy BA, Dajani KA, Whelan DB, et al. Decision making in the multiligament-injured knee: an evidence-based systematic review. Arthroscopy 2009; 25(4): 430-8

[83] Bhandari M, Zlowodzki M, Tornetta P, 3rd, Schmidt A, Templeman DC. Intramedullary nailing following external fixation in femoral and tibial shaft fractures. J Bone Joint Surg Am 2005; 19(2): 140-4.

[84] Nowotarski PJ, Turen CH, Brumback RJ, Scarboro JM. Conversion of external fixation to intramedullary nailing for fractures of the shaft of the femur in multiply injured patients. J Bone Joint Surg Am 2000; 82(6): 781-8.

(c) Bertrand et al.; Licensee Bentham Open.

This is an open access article licensed under the terms of the Creative Commons Attribution Non-Commercial License (http://creativecommons.org/licenses/by-nc/3.0/) which permits unrestricted, non-commercial use, distribution and reproduction in any medium, provided the work is properly cited. 